\title{
Anabases
}

ANABASES Traditions et réceptions de l'Antiquité

$9 \mid 2009$

Varia

\section{Images des vestiges préislamiques de l'Ifrîqiya chez les géographes arabes d'époque médiévale}

\section{Anna Caiozzo}

\section{(2) OpenEdition}

1 Journals

Édition électronique

URL : http://journals.openedition.org/anabases/386

DOI : 10.4000/anabases.386

ISSN : 2256-9421

Éditeur

E.R.A.S.M.E.

\section{Édition imprimée}

Date de publication : 1 mars 2009

Pagination : 127-145

ISSN : 1774-4296

\section{Référence électronique}

Anna Caiozzo, «Images des vestiges préislamiques de l'Ifrîqiya chez les géographes arabes d'époque médiévale », Anabases [En ligne], 9 | 2009, mis en ligne le 01 mars 2012, consulté le 20 octobre 2019. URL : http://journals.openedition.org/anabases/386 ; DOI : 10.4000/anabases.386

(c) Anabases 
Anabases 9 (2009), p. 127-145.

\section{Images des vestiges préislamiques de l'Ifrîqiya chez les géographes arabes d'époque médiévale}

Anna Caiozzo

EN DÉCEMBRE 2003, notre regretté collègue Claude Liauzu qui occupait à l'Université Paris Diderot la chaire d'Histoire du Maghreb, organisait dans le cadre du CMCU son dernier colloque " Décolonisation, regards croisés Orient-Occident ${ }^{1}$ ». Il m'avait alors demandé de présenter le regard des lettrés musulmans d'époque médiévale sur le passé préislamique de l'Ifrîqiya ou, tout au moins, les bribes qui leur étaient encore accessibles et les représentations connues de cette région dans les manuscrits à peintures.

Pourtant, l'entreprise était malaisée, en raison de deux obstacles principaux. Lorsque l'on explore les corpus enluminés des cosmographies médiévales orientales, il apparaît assez vite que les peintres et miniaturistes du monde musulman ne représentent pour ainsi dire jamais les lieux remarquables de l'Occident musulman : lieux du présent ou du passé sont confondus dans une même ignorance. À peine peut-on voir dans une cosmographie mongole une miniature de la reine des Nûbî faisant jeter un voyageur hors des murailles de sa ville ${ }^{2}$. Et, en effet, pour le géographe ou le cosmographe oriental, la plupart des merveilles du monde, des lieux exceptionnels (en ruines ou non) ou relatifs aux grands événements du passé, se situent en Orient, du Levant jusqu'à la Chine. Quant aux géographes ayant visité ou décrit le Maghreb et l'Ifrîqiya, ils se montrent relativement ignorants de son histoire, exception faite cependant d'alBakrî ou d'al-Idrîsî.

1 Programme scientifique d'échanges entre l'Université de la Manouba (Tunisie) et l'Université Paris Diderot.

2 Tûsî Salmânî, 'Ajâ'ib al-Makhlûqât wa gharẩib al-mawdjûdât, Paris, B.n.F., sup. persan 332, Bagdad, 1388, fol. 202vº. 
L'Ifrîqiya fut en effet à la fois peu étudiée par les historiens musulmans, et peu visitée par les géographes, pour des causes qui tiennent certes à sa situation géographique excentrée au sein du Dâr al-Islâm, mais aussi à la méconnaissance de l'histoire de cette région, y compris par ses propres habitants, les Berbères, et ce faute de sources écrites $^{3}$. Jean Léon l'Africain, dans sa Description de l'Afrique, tente d'expliquer l'inexistence de sources par la destruction des ouvrages par les conquérants arabes, thèse au demeurant habituellement retenue par l'historiographie ${ }^{4}$.

Cette difficulté d'accès aux sources eut de notables répercussions sur les savoirs plus que sur les imaginaires géographiques et historiques, et ce en dépit des rapports constants qui avaient existé entre le Maghreb central et occidental et le monde romain puis byzantin ${ }^{5}$. En outre, il règne une certaine indifférence parmi les historiens orien-

3 Cette réflexion n'aurait pu exister sans le travail fondateur d'Ahmed SIRAJ, L'image de la Tingitane, L'historiographie arabe médiévale et l'antiquité nord-africaine, École Française de Rome, 1995. Toutefois, la zone géographique couverte par son investigation s'arrêtait aux portes de l'ancienne province de Numidie, même si l'exploration avait souvent évoqué bien des aspects de l'Ifrîqiya : A. SirAJ, L’image, p. 197-198. Le seul à écrire tardivement une histoire des Berbères est l'historien tunisien Ibn Khaldûn au XIV siècle : Histoires des Berbères et des dynasties musulmanes de l'Afrique septentrionale, MAC GUCKIN DE SLANE (éd.), Paris, 1999, 4 vol.

4 Jean Léon l'Africain, Description de l'Afrique, Tierce partie du monde escrite par Jean Léon African, premièrement en langue arabesque, puis en toscane et à présent mise en françois: J. Temporal (éd.) et C. Schefer, Paris, 2000, vol. 1, p. 47-48 : "Tous les ouvrages historiques que les Arabes possèdent sur les Africains sont traduits de la langue latine. Ce sont des œuvres anciennes certainement écrites au temps des ariens et d'autres probablement auparavant. [...] Au temps où régnèrent en Afrique les schismatiques, j'entends ceux qui avaient fui les pontifes de Bagdad, ils donnèrent l'ordre de brûler tous les livres d'histoire et de science des Africains. Il leur parut en effet que ces ouvrages étaient susceptibles de maintenir les Africains dans leur vieil orgueil, de les amener à la rébellion et de leur faire renier leur foi mahométane... C'est ce qui est advenu aux Perses sous la domination arabe. Eux aussi ont perdu leur écriture et tous leurs livres ont été brûlés sur l'ordre des pontifes mahométans [...] Romains et Goths avaient fait de même quand, ainsi qu'on l'a dit, ils avaient gouverné la Berbérie. "

5 A. Siraj, L'image, p. 174-175. Voir notes 5-6 : «'Umar al-Khattâb qualifie l'Ifrîqiya de pays perfide, qui égare et qui trompe."

"Dans un article consacré à la connaissance de l'umma chez les historiens de l'islam, C. CAHEn ["Réflexions sur la connaissance du monde musulman par les historiens", Folia Orientalia XII (1970), p. 41-49] a remarqué le contraste qui existe entre la conscience profonde de l' umma chez les musulmans et l'indifférence des historiens envers la connaissance de l'histoire des différents peuples constituant cette 'umma. Le Maghreb est l'une des régions pour lesquelles les historiens arabes n'ont pas manifesté un véritable intérêt. Pourtant elle fut l'une des parties de l'empire de l'Islam les plus importantes économiquement et les plus agitées politiquement. En revanche, et pour aller au bout de la problématique posée par Claude Cahen, tout en la mettant en rapport avec l'histoire préislamique de la région, nous dirons qu'à cette indifférence apparente envers l'histoire ancienne de l'Afrique du Nord, les historiens arabes n'ont pas hésité à consacrer des chapitres entiers 
taux vis-à-vis de l'histoire du Maghreb comparée à leur intérêt manifeste pour l'histoire des peuples plus orientaux (Persans en particulier) ${ }^{6}$. Chez al-Mas'ûdî, l'histoire du Maghreb se résume en une série de légendes. De ce fait, en l'absence de sources écrites, l'existence de ruines revêt toute son importance comme porteuse d'une mémoire permettant à la fois la prise de conscience d'un passé original, et l'élaboration d'une image tangible de ce passé.

Parmi les sources géographiques que l'on peut évoquer figurent les cosmographies, les témoignages des géographes voyageurs et celui des compilateurs dont l'œuvre revêt une connotation géographique. Les cosmographies jouèrent un rôle non négligeable dans l'appréhension de l'espace historique réel et surtout imaginaire dans lequel évoluaient les peuples arabo-musulmans. Soulignons qu'il existe une tradition importante et très prisée à partir du $\mathrm{x}^{\mathrm{e}}$ siècle des 'Adjẩib al-makhlûqât wa gharẩib al-mawdjûdât ou géographie des merveilles et qui donna lieu à une abondante littérature représentée entre autres par Ibn al-Faqîh al-Hamadhânî (m. 903), ou par l'Abrégé des Merveilles que l'on s'accorde à attribuer à al-Mas'ûdî, décrivant les vestiges orientaux en particulier, réels (ceux d'Égypte) ou imaginaires (la muraille de Gog et Magog) ${ }^{7}$. Mais qu'en est-il de l'Afrique du Nord et surtout de l'Ifrîqiya ? En fait, peu de ces cosmographes et historiens universels les ont évoquées, pas plus Ibn al-Faqîh dans le Kitâb al-buldân ${ }^{8}$ (Livre des pays), qui reprend le descriptif d'Ibn Khurradâdhbih ponctué d'anecdotes, qu'al-Mas'ûdî (m. 956) dans les Murûdj al-dhahab ou qu'al-

pour parler de l'histoire ancienne d'autres nations non-musulmanes. Ainsi nous trouvons dans les livres de l'histoire universelle des parties relatives à l'histoire des rois de la Chine, des Chaldéens, des Assyriens, des Perses, des Grecs, des Romains, et des Byzantins... en plus des grandes nations anciennes; les œuvres des historiens arabes consacrent des passages aux diverses populations de l'œkoumène. [...] existait-il une histoire ancienne du Maghreb chez les populations berbères de la région au moment de l'arrivée des Arabes ? c'est une question qui restera certainement énigmatique. C'est là, à notre avis, où réside justement la grande lacune de l'histoire maghrébine" (A. SIRAJ, L'image, p. 192-193). L'historiographie du Maghreb est peu évoquée par les historiens musulmans alors que bon nombre d'entre eux ont parlé de l'histoire de l'Antiquité des Perses et de l'Inde ou de la Grèce, depuis al-Yaqûbî, dans son Tarîkh, al-Tabarî, al-Mas'ûdî, al-Maqdisî. D'après A. Siraj, s’il n'y a pas d'histoire des Berbères avant Ibn Khaldûn, c'est peut-être parce que la conscience d'une histoire spécifique n'existe pas chez les Berbères eux-mêmes (ibid., p. 193).

7 J.-L. Bacqué-Grammont, F. De Polignac, G. Bohas, "Monstres et murailles, Alexandre et bicornu, mythes et bon sens. Quelques notes", Figures mythiques des mondes musulmans, Revue des Mondes Musulmans et de la Méditerranée 89-90 (2000), p. 109-127.

8 H. MAssé, Abrégé du Livre des pays, IFEAD, Damas, 1973.

9 Mas'ûdî, Les Prairies d'or, C. Barbier de Meynard, A. Pavet de Courteille, C. Pellat (éd.), Paris, 1966-1979, 7 vol. 
Maqdisî (m. 966) dans son Livre de la création ${ }^{10}$, voire al-Dimashqî (m. XIII ${ }^{\mathrm{e}}$ siècle) ${ }^{11}$, très parcellaire, qui donne des indications sur quelques villes. Dans la Tuhfat al-albâd ${ }^{12}$ (Cadeaux des coeurs) et dans al-Mu'rib 'an ba'd fî 'adjầib al-Maghrib ${ }^{13}$ (L'étonnant sur les merveilles du Maghreb), Abû Hâmid al-Gharnâtî al-Andalûsî (m. 1170), n’évoque véritablement que les merveilles préislamiques du Maghreb al-Aqsâ (la cité de cuivre, les colonnes d'Hercule, la Mer des ténèbres, la venue d'Alexandre, etc.) mais jamais celles de l'Ifrîqiya ${ }^{14}$.

Quant à la véritable littérature géographique, celle des voyageurs - marchands, pèlerins, espions - on n'a cependant pas la certitude qu'ils aient tous visité la région. Peut-être, Ibn Khurradâdhbih (m. 885) avec Les Itinéraires et les royaumes ${ }^{15}$ (Masâlik wa'l-mamâlik), al-Yaqûbî (m. 897) et ses Pays ${ }^{16}$ (al-buldân) centrés sur l'Irak, seraient venus en Afrique du Nord ; al-Istakhrî (m. 951), dont on ne sait s'il a visité ou non le Maghreb et dont les Masâlik wa'l-mamâlik restent évasifs ${ }^{17}$; al-Muqaddasî ${ }^{18}$ (m. 966), voyageant certes en Orient mais ignorant visiblement l'Occident ; Ibn Hawqal ${ }^{19}$ (m. 988), dans son Sûrat al-'ard, donne des indications sur les activités et les hommes ; Ibn Sa'îd al-Maghribîi ${ }^{20}$ (m. 1286) d'origine andalouse, voyagea en Orient, mais sa géographie s'inspire beaucoup d'al-Bakrî et néglige l'aspect historique ; al-'Umarî ${ }^{21}$

10 Al-Maqdisî, Kitâb al-Bad' wa al-Târîkh, Le livre de la création et de l'histoire, C. HuART (éd.), 1899, 6 vol.

11 Al-Dimishqî, Nukhbat a-dahr fî̀ 'adjầib al-bar wa-l-bahr, Chef d'œuvre des temps sur les merveilles de la terre et de la mer, Manuel de cosmographie du Moyen Âge, A.F. MeHren (éd.), Saint-Pétersbourg, 1866 (éd.), Copenhague, 1874 (trad.).

Ibn Abî al-Rabî', Tuhfat al-Albâd, El regalo de los espiritus, A. Ramos (éd.), Madrid, 1990.

13 Abû Hamîd al-Gharnatî, Muhammad ibn 'Abd-al-Rahmân ibn Suleyman ibn Abî alal-Rabî', Elogios de algunas maravillas dal Magrib, I. Bejarano (éd.), Madrid, 1991.

14 Voir sur les merveilles dans cette partie du monde, C. PICARD, "Récits merveilleux et réalité d'une navigation en Océan Atlantique chez les auteurs musulmans", in Miracles, Prodiges et Merveilles au Moyen Âge, XXV Congrès de la SHMES (Orléans, juin 1994), Paris, 1995, p. 75-87. Ibn Khordadhbeh, al-Masâlik wa'l-mamâlik, in R. Blachère, H. Darmaun (éd.), Extraits des principaux géographes arabes, Paris, 1957, vol. 1, p. 17-21 et M. HADJ SADOK, Description du Maghreb et de l'Europe au III' siècle / IX siècle, Alger, 1949. Yakubî, Les Pays, G. WIET (éd.), Le Caire, IFAO, 1937.

17 A. DHinA, "Al-Içt'akhrî, Kitâb al-Masâlik wa'l Mamâlik, (Le livre des itinéraires et des Royaumes)", Bulletin d'Études Orientales 37 (1948), p. 91-96.

Al-Muqaddasî, Description de l'Occident musulman au X siècle par al-Muqaddasi, C. PeLlat (éd.), Alger, 1950.

19 Ibn Hawqal, Configuration de la terre, G. WiET, J. H. Kramers (éd.), Paris, Maisonneuve, 1964 et Configuracion del mundo, fragmentos alusivos al Magreb y Espana, M.J. RoMANI SuAY (éd.), Valence, 1971. Ibn Sa'id Gharnatî, Kitâb al-bidâ', in E. FAGNAN (éd.), Extraits inédits relatifs au Maghreb (Géographie et histoire), Alger, 1924. 
(m. 1349), compilateur d'époque mamelouke, dans son Masâlik al-absâr présente des listes de villes et raconte les faits marquants ; d'autres, Ibn Djubayr et Ibn Battûta ${ }^{22}$, n'ont hélas pas laissé de récits sur l'Ifrîqiya, ce que l'on ne peut que regretter dans le cas du premier qui ne fit que du cabotage pour aller en Égypte; quant au second, ses descriptifs n'incluent jamais de notice sur les villes. Enfin, al-Wazzân (1496-1548), dit Jean Léon l'Africain ${ }^{23}$, lettré d'origine cordouane au service du sultan de Fès, capturé par des pirates et converti au catholicisme, offre un ouvrage écrit en italien, témoignage de ses voyages, riche d'érudition et de précisions sur les villes et les ruines.

Il existe enfin une autre catégorie de géographes : celle des compilateurs, précieux car utilisant des sources éminemment utiles comme al-Warrâq (m. 973), voyageur d'origine espagnole qui parcourut le Maghreb au $\mathrm{x}^{\mathrm{e}}$ siècle et écrivit un ouvrage aujourd'hui perdu sur les itinéraires et les royaumes d'Afrique, le Kitâb fî masalik wa mamâlikiha $\hat{a}^{24}$. Al-Bakrî̀ ${ }^{25}$ (m. 1094) est le plus représentatif de ce courant géographique avec son Livre des itinéraires et des royaumes. Auteur d'origine espagnole, il est la source la plus ancienne et la plus précieuse que l'on possède pour la description du Maghreb et de l'Ifrîqiya. Bien entendu, il utilise des sources antérieures, tel al-Warrâq, et s'attarde surtout sur les villes anciennes; mais il écoute aussi les récits des voyageurs et commerçants. Parmi ses continuateurs, adeptes des itinéraires et des routes, le chérif al-Idrîsîi ${ }^{26}$ (m. 1166), le géographe anonyme du XII ${ }^{\mathrm{e}}$ siècle $^{27}$, compilateur d'al-Bakrî et proche du prince almohade al-Mansûr en 1191, qui écrivit le Kitâb al-ibtisâr fî̀ 'adjầib al-masa. Compilateur mais aussi voyageur, le prince ayyûbide Abû'l-Fidâ' ${ }^{28}$ (m. 1331) qui annonce sa volonté de faire une compilation exhaustive dans son Takwîn al-buldân (Disposition des pays) où il reprend al-Idrîsî, et Ibn Sa'îd al-Maghribî. Signalons un autre compilateur d'al-Bakrî́29, al-Watwât (m. 1318) et son Manâhidj al-fikar wa manâhidj al-'ibar, originaire d'Espagne mais vivant en Égypte ${ }^{30}$.

Quelles images ces auteurs livrent-ils des ruines, et surtout quel rôle ont-elles pu jouer dans la reconstitution du passé de l'Ifrîqiya?

P. Charles-Dominique, Voyageurs arabes, Paris, 1995.

Jean Léon l'Africain, Description de l'Afrique.

R. BRUnSCHVIG, "Un aspect de la littérature historico-géographique de l'Islam", in A. TURKI (éd), Études d'islamologie, 1, Paris, 1976, p. 51- 62 et p. 55. Issu d'une famille espagnole de Guadalajara, il naquit à Kairouan et vécut ensuite chez al-Hakam et composa pour lui $F \hat{\imath}$ masâlik Ifrîqiya wa mamâlikihi; il représente donc une source du $\mathrm{X}^{\mathrm{e}}$ siècle très importante. El-Bekri, Description de l'Afrique septentrionale, Mac Guckin de SLane (trad.), Paris, 1965. Idrîsî, La première géographie de l'Occident, Chevalier JauberT, trad. revue par A-L. NeF, Paris, 1999.

Géographe anonyme, L'Afrique septentrionale au XIf siècle de notre ère, description extraite du Kitâb al-Ibtiçâr, E. FAGnAN (éd.), Constantine, 1900.

Abûll-Fidâ', A. Reinaud (éd.), Géographie d'Aboulféda, Paris, 1848 et Aboulféda, Description des pays du Maghreb, C. SOLVET (éd.), Alger, 1839 (rééd. Francfort, 1998).

E. FAGNAN, Extraits inédits, p. 38-69.

Ibid., p. 41 sq. 


\section{Images fugaces d'un passé mal connu}

\section{Une province nommée «Afrique»}

L'Ifrîqiya est, pour les auteurs musulmans, une province difficile à définir ; son nom viendrait d'Africa, nom utilisé bien avant l'époque romaine pour désigner les territoires contrôlés par Carthage ${ }^{31}$, mais dont les limites demeurent quelque peu aléatoires selon les époques. L'espace concerné fait l'objet de nombreuses confusions de la part des historiens et géographes arabes. Selon Ibn Khurradâdhbih (m. 885), il s'agirait du royaume aghlabide; Ibn Hawqal l'augmente considérablement en territoires ${ }^{32}$ et, selon al-Bakrî́33, il s'étendrait dans tout le Maghreb, alors qu'Abû'l-Fidâ' précise qu'il se limite au Maghreb central ${ }^{34}$. Jean Léon l'Africain, dans sa Description de l'Afrique ${ }^{35}$, fournit sans conteste une définition en apparence fantaisiste mais bien peu éloignée de la réalité et de la place réelle de l'Afrique dans l'imaginaire oriental.

Ainsi, l'Ifrîqiya, parfois identifiée à l'ensemble du Maghreb, parfois limitée géographiquement à une seule province, correspond en réalité à l'ancienne Numidie et Byzacène, comprenant un morceau de Tripolitaine, et une partie des Aurès. De ce fait elle englobe surtout l'émirat aghlabide, puis l'émirat zîrîde et enfin la province hafside ; elle s'étend donc d'Alger à Tripoli et peut aller jusqu'à Sirt, et elle englobe aussi quelques villes de la côte et de l'intérieur des terres dont certaines eurent un prestigieux passé (Carthage, Bône, Lepede, Leptis Magna), et couvre donc, pour une grande part, le territoire de l'actuelle Tunisie. Il s'agit donc d'un ensemble géographique exceptionnel pour ses trésors de ruines préislamiques et qu'aucun géographe ne peut ou ne devrait manquer dans ses pérégrinations.

\section{Les habitants des siècles passés et les populations non arabes}

Les géographes inscrivent le descriptif de la ruine dans une évocation très générale du passé de la région à laquelle participent aussi les types de populations rencontrées, les religions autres que l'Islam, les habitudes culturelles (alimentaires notamment). Signalons que les géographes reconnaissent les Berbères comme étant de très anciennes populations locales que l'on pense venues d'Orient - parfois même rattachées à Goliath (Djâlût ${ }^{36}$-,

\footnotetext{
31 M. TAlbi, "Ifrìkiya”, E.I. ${ }^{2}$, III, p. 1073-1076.

32 Ibn Hawqal, Configuración del mundo, M. J. Romani SuaY (éd.), Valence, 1971, p. 9.

33 El-Bekri, Description, p. 49.

34 Abû'l-Fidâ', Description, p. 5.

35 Jean Léon l'Africain, Description, vol. 1, p. 1-2. "Ce nom l'Ifrîqiya dérive d'Ifricos, roi de l'Arabie Heureuse, lequel fut le premier qui vint l'habiter. "

36 Chez Mas'ûdî, les Berbères descendent de Goliath, voir Prairies d’or, vol. 1, p. 41, $\$ 93$.
} 
de Palestine essentiellement selon Ibn Khurradâdhbih ${ }^{37}$, al-Maqdisî ${ }^{38}$ et d'autres encore. Al-Yaqûbîi ${ }^{39}$ précise : "Les habitants descendent des anciens Romains qui, autrefois, en formèrent la population : on y compte aussi des Berbères ${ }^{40} \ldots$.. Ainsi la conscience d'une diversité des populations est relativement présente car il renchérit plus $\operatorname{loin}^{41}$ en précisant que dans la région du Djarîd, c'est-à-dire Tûzar (Tozeur), Hamma (Aquae), Taqiyûs (El-Oudiane), Nafta (Nepte), les habitants sont des non-Arabes, descendants d'anciens Romains, de Berbères et d'Afâriqa.

Le peuplement romain et surtout byzantin est lui aussi bien appréhendé par le géographe anonyme ${ }^{42}$ qui fournit en outre une explication sur la coexistence entre Berbères et Francs - les Byzantins - qui occupaient l'Afrique et qui se partagèrent le pays, les uns sur la côte, les autres dans les montagnes, jusqu'à la conquête musulmane ${ }^{43}$. Dans l'ensemble, la connaissance des populations ayant occupé l'Ifrîqiya est peu précise dans le temps, et vague dans les appellations. Quant aux Vandales, on en ignore même l'existence. Tous les voyageurs ont cependant conscience que des peuples différents, allogènes, Berbères, Romains, Byzantins, se sont succédés sans que les lieux ni les circonstances de leur installation ne soient bien identifiés ${ }^{44}$. Les chrétiens sont crédités d'un a priori positif comme ayant apporté le monothéisme en Afrique, comme le signale al-Bakrî̀ ${ }^{45}$. La distinction entre "Rûms » ou «Ifranj, » est peu claire, le lecteur ne sachant jamais s'il s'agit de Romains, de Byzantins, ou de Siciliens normands ; une différence est cependant faite en Tripolitaine entre les coptes et les autres chrétiens.

37 Ibn Khurradâdhbih, Le livre des itinéraires et des provinces d'ibn Khordabeh, C. BARBIER DU MeYnard (éd.), Paris, Imp. Impériale, 1865, p. 213 : "Les Berbères d'abord domiciliés en Palestine obéissent au roi Djalût. Lorsque ce roi fut tué par David, ils émigrèrent en Occident. »

38 Al-Maqdisî, Le livre de la création, vol. 4, p. 78 et p. 64-65 : "Les Berbères se rattachent aux Amalécites qui habitaient la Syrie et la Palestine et dont le reste après les combats livrés par Josué fils de Nûn, et le massacre qui en fut fait, se retira dans les parties hautes du Maghreb. "

39 Al-Yakûbî, Livre des pays, G. WIET (éd.), IfaO, Le Caire, 1937, p. 202-203.

$40 \quad$ Ibid., p. 203. De même, 'Adjadâbiya en Cyrénaïque : "Certains habitants affirment d'être les descendants de famille de la tribu de Lakhm, qui émigrèrent de Syrie dans la région. D'autres, enfin, se disent d'origine romaine. "

41 Ibid., p. 213.

42 Kitâb al-Ibtisâr, in E. FAGNAN (éd.), Extraits inédits, p. 77 : « Les Berbères en effet dont la patrie était le pays de Palestine en Syrie.»

43 Ibid., p. 78.

44 Ibn Sa'îd Gharnatî, Kitâb al-bidâ', in E. FaGnan (éd.), Extraits inédits, p. 7 : «'Uqba ibn Nafî' [en arrivant] trouva les Rûms et les Berbères répandus dans le pays comme une nuée de sauterelles. »

45 El-Bekri, Description, p. 96. : "Ishâq ibn 'abd al-Malik al-Malshûni déclare (cependant) qu'aucun des prophètes n'entra en Afrique, et que ce furent les disciples de Jésus, fils de Marie, qui, les premiers, y apportèrent la vraie foi. » 


\section{La toponymie, élément de connaissance du passé ?}

Itinéraires et voies anciennes constituent les traces les plus édifiantes de ce passé préislamique, les anciennes routes (hormis leur dégradation matérielle) demeurent toujours à l'époque médiévale des itinéraires fréquentés ${ }^{46}$. L'intérêt des géographes pour les diverses localités résume les progrès de la géographie humaine et l'avancée de l'urbanisation en Afrique du Nord après la conquête musulmane. Toutefois l'ancienneté du réseau urbain se mesure aussi à l'évocation de la toponymie et au point d'honneur que mettent certains géographes à en expliciter l'étymologie et la variété.

Par exemple, al-Bakrî explique la signification d'Atrabulis ou " Tripoli " par l'étymologie grecque "trois villes " fondées par l'empereur Sévère ${ }^{47}$. D'autres villes rebaptisées par les conquérants musulmans sont fièrement présentées, telle Tunis par al-Idrîsî ${ }^{48}$, ou Barqa citée par Abû'l-Fidầ ${ }^{49}$. Toutefois, lorsque l'étymologie est mal connue, mais l'importance de la ville notoire, les auteurs y suppléent par des détails touchants, souvent inutiles, mais témoignant d'une conscience certaine quant à l'importance du site ${ }^{50}$.

L'ensemble des témoignages révèle donc une connaissance avérée de la richesse historique de l'Ifrîqiya, celle de son passé grec, numide, romain puis byzantin, avant la conquête musulmane, et de la diversité de son peuplement. Pourtant l'évocation de ce passé ne fait jamais l'objet d'une exposition claire et chronologiquement ordonnée, mais le tout demeure le plus souvent confus, amalgamé et sans identification précise des localisations et des trames chronologiques.

\section{Les ruines, lieux de mémoire ou restes anecdotiques du passé ?}

\section{Un problème insurmontable, la datation des monuments}

Tous les auteurs attestent l'origine ancienne des cités mais sans pouvoir situer leur construction dans le temps. Les récits les plus décevants et cependant conformes aux nouveaux principes de géographie humaine qu'ils inaugurent, sont à la fois celui d'alMuqaddasî et celui d'Ibn Hawqal. Ce dernier aurait visité le Maghreb, et si la plupart de ses descriptifs font mention de murailles, de leur nature (pierre, adobe, paille) et leur degré de solidité, il ne précise jamais leur origine ni leur date de construction, à l'exem-

A. SiRAJ, L'image, p. 365-436.

El-Bekri, Description, p. 19-20.

Idrîsî, La première géographie, p. 187-188.

Abû'l-Fidâ, Description, p. 25.

Ibid., p. 111.
} 
ple de Tunis ${ }^{51}$ ou Cherchell ${ }^{52}$. Al-Muqaddasî signale pour sa part que Constantine (Qustantîna) est une ville " antique ", préislamique, à deux jours de marche de la capitale ${ }^{53}$; que Tâhert est de fondation " ancienne " et qu'à proximité se trouve une ville en ruines appelée Ruhâ ${ }^{54}$. Ce sont de semblables vocables que tous emploient pour qualifier les villes antiques ou préislamiques ("ville ancienne "; "bâtie par les Africains "; "bâtie par les anciens Africains "; " ville très ancienne "; " dotée de murailles "), comme le montrent al-Bakrî̀ ${ }^{55}$, Abû'l-Fidâ' ${ }^{56}$ et d'autres encore. Jean Léon l'Africain est plus précis, car il attribue l'origine des villes à une période donnée (africaine ou pré-romaine, romaine, gothique) mais sans avancer de date de fondation et utilise la formule consacrée " antique et bâtie par les Romains ${ }^{57}$ ", "par les Africains ${ }^{58}$ ", ou "par les Goths 59 ".

\section{Les événements remarquables : des légendes de fondation à la ruine des villes}

Certains géographes tentent de retracer l'histoire de la ville - ou tout au moins des faits marquants - mais ils le font le plus souvent de façon anecdotique et en relation avec des faits mythiques et légendaires. Évoquant Tunis, al-Bakrî écrit :

Lors de la conquête de Tunis, les habitants demandent à 'Abd al-Malik d'envoyer de l'aide et ils disent : «C'est une de ces villes saintes dont les habitants seront reçus dans la miséricorde divine ; c'est le boulevard d'al-Makedounia ${ }^{60}$ !"

Car ici subsiste le souvenir d'Alexandre le Grand et de son périple occidental. Al-Bakrî cite encore le souvenir des patriarches Moïse ou al-Khidr sur le lac de Radès ou Napoli ${ }^{61}$. Le point d'orgue concerne cependant la cité de Carthage pour laquelle les auteurs se montrent prodigues en détails peu clairs. Ces informations seraient, d'après al-Bakrî, empruntées à al-Djazzâr, un célèbre médecin cordouan, qui racontait une

59

Ibn Hawqal, Configuration, vol. 1, p. 70.

Ibid., p. 73.

Al-Muqaddasî, Description, p. 21.

Ibid., p. 23.

El-Bekri, Description, p. 278. Ibid., p. 155 : Satîf, p. 136 : Milîana, p. 41 : Qâbîs (Gabes).

Abû'l-Fidâ, Description, p. 19.

Jean Léon, Description, vol. 3, p 80, p. 88, p. 90-91, p. 93, p. 95-96, p. 102, p. 107, p. 110 , p. 113 , p. 117 , p. 119 , p. 130 , p. 148 , p. 152 , p. 154 , p. 170 , p. 180 , p. 182 , p. 257, p. 259 , p. 278.

Ibid., p. 125 , p. 130 , p. 278.

Ibid., p. 151.

El-Bekri, Description, p. 81 (Alexandre de Macédoine).

Ibid., p. 83 : "Ce fut là que Moïse quitta al-Khiḍr que la bénédiction soit sur eux. " 
légende répandue en Ifrîqiya au $\mathrm{x}^{\mathrm{e}}$ siècle ; ce texte relate l'interrogatoire d'un vieillard par Mûsâ Ibn Nusayr, comme cela dut probablement être le cas, par les premiers conquérants. On remarque à ce propos qu'al-Bakrî n'hésite pas à reprendre, suivant en cela al-Djazzâr, un passage des Annales de Tacite et de l'Histoire romaine de Tite Live ou de Paul Orose. L'utilisation de ces extraits démontre que les œuvres des auteurs latins circulaient vraisemblablement en Occident musulman au XI ${ }^{\mathrm{e}}$ siècle. On sait en effet que les califes de Cordoue firent traduire des ouvrages envoyés par l'empereur byzantin $^{62}$.

On dispose par ailleurs de nombreux récits attribués aux musulmans concernant le destin de Carthage, de ses origines jusqu'à sa destruction complète. Selon Ibn Sa'îd :

Carthage capitale de l'Ifrîqiya avant l'Islam. La construction est ancienne et remonte dit-on à Adrîche (Dirûn ou Didon) prince rûmi d'Ifrîqiya. [...] elle fut détruite du temps de 'Abd-al-Malik Ibn Marwân, et l'on transporta les produits du pillage à Bagdad ${ }^{63}$.

Pour al-Bakrî́ ${ }^{64}$ la cause de sa chute remonte à Hannibal et à ses ambitions romaines. Si la ville de Carthage fascine encore et que le peuple carthaginois, ses origines, sa chute sont toujours évoqués de façon relativement exacte, en revanche, le silence est absolu sur l'épisode vandale, dont seul Jean Léon l'Africain se fait l'écho ${ }^{65}$. Quant à la domination byzantine préislamique, elle reste insaisissable malgré les nombreuses mentions d'ouvrages fortifiés attribués à cette époque mais sans précision sur les auteurs. Ibn 'abd al-Hakam identifie bien les Berbères comme habitants de la région et les Rûms (Byzantins) comme « étrangers » ou " nasrâniyya », donc occupants postérieurs, et précise que certains Berbères tels les Barânis sont devenus chrétiens comme les Rûms ${ }^{66}$. Une autre ville célèbre, Bône / Annaba, autrefois Hippone, est connue des géographes et al-Bakrî l'associe parfaitement à saint Augustin ${ }^{67}$. Quant à Béja, bien plus ancienne, ses origines remonterait au temps de Jésus ${ }^{68}$. Enfin, Sbeitla / Subaytila (Sufeitula) est rattachée via le patrice Grégoire, à l'époque byzantine ${ }^{69}$.

La fondation des villes est ainsi souvent datée par des références à des événements ou à des personnages célèbres (Scipion, al-Khidr, Jésus, saint Augustin, le patrice Grégoire). Les détails, quand ils existent, relèvent d'emprunts effectués dans des textes d'histoire romaine. Toutes les périodes - pré-romaine, romaine ou byzantine - sont indistinctement évoquées. La dégradation de la cité et de ses monuments est, quant à

A. SIRAJ, L'image, p. 224-225.

Ibn Sa'îd, Kitâb al-bidâ', p. 9.

El-Bekri, Description, p. 89-90, p. 92.

Jean Léon l'Africain, Description, vol. 3, p. 47, p. 117, etc.

Ibn 'Abd al-Hakam, Conquête de l'Afrique du nord et de l'Espagne, A. GATEAU (éd.), Alger, 1948 , p. 81.

Jean Léon l'Africain, Description, vol. 3, p. 116.

Ibid., p. 128-119.

Ibid., p. 203-04, origine reprise par al-Dimishqî, Cosmographie, p. 337. 
elle, attribuée à l'œuvre du temps et surtout aux vagues successives de conquérants. La chute de Carthage est par ailleurs expliquée de façon plus nuancée, à la fois comme vengeance des Romains et comme l'œuvre de la conquête arabe et des populations plus récentes islamisées occupant le site $^{70}$, ce qui apparaît de toute évidence comme une volonté délibérée de placer les conquérants arabes dans la continuité de son exceptionnel destin et de leur en attribuer la chute, signe de leur indiscutable prééminence !

Ainsi, à la seule exception de Carthage ${ }^{71}$, les géographes semblent avoir du mal à relater les circonstances exactes de la fin des cités antiques et de la ruine de leurs monuments ; il peut d'ailleurs nous sembler étrange qu'au cours de ces récits la fin des villes antiques soit fréquemment attribuée aux populations locales, voire aux conquérants arabes, sans penser qu'elles eurent à subir l'assaut dévastateur des Romains, des Vandales, puis enfin de la reconquête byzantine et que beaucoup de leurs monuments n'étaient déjà plus entretenus à l'époque chrétienne. Quoi qu'il en soit, ce n'est jamais l'œuvre du temps qui est mise en cause, mais celle des hommes, soit par les conquêtes successives, soit par le remploi des matériaux précieux ${ }^{72}$.

\section{Identifier la ruine}

Une fois un cadre chronologique sommaire mis en place, les géographes nomment alors ce qu'ils voient émerger de ce passé. Le plus souvent d'ailleurs, ce sont des restes anonymes qui nous sont décrits par al-Bakrî̀ ${ }^{73}$ ou al-Idrîsî ${ }^{74}$.

Outre l'ancienneté de la ville et sa notoriété (madîna djalîla : ville illustre), tous évoquent les ruines impressionnantes de certains sites et surtout des murs d'enceinte et autres murailles remarquables pour leur épaisseur, leur hauteur (sahir, avec hisn / husûn), à l'aide de termes génériques (âthâr qadîma: monuments anciens et édifices antiques; âthâr 'azîma: ruines énormes, immenses).

Les monuments les plus couramment décrits sont généralement les équipements publics, les lieux de spectacle, les lieux sacrés (de culte, sépultures) et les lieux fortifiés. Les équipements de voirie les plus cités demeurent les thermes (hammâmât) ; les aqueducs ( $m \hat{a}$, mais aussi désignés par le terme de voûte $: q a b \hat{u}=a q b i y a t ~ l a q b \hat{a})$; les citernes et réservoirs (mûâdjal). Sont aussi cités les lieux curieux tels les grottes, les lieux souterrains (ghayrân), ou les matériaux précieux (le marbre : ruhâm), etc. Pourtant, le monument décrit n'est pas toujours bien identifié et nommer le vestige ne semble pas une entreprise

Ibid., p. 22.

Kitâb al-Ibtisâr, in E. FAGNAN (éd.), p. 20-22.

Dans Le Génie du christianisme (L.III V 3), Châteaubriant explique qu'il existe au fond deux sortes de ruines, celles du temps, et celles des hommes qui sont en fait de ruines, des dévastations.

El-Bekri, Description, p. 47, p. 121, p. 106, p. 130, p. 194.

Idrîsî, La première géographie, p. 156, p. 158, p. 159, p. 179-181, p. 183, p. 199. 
aisée. C’est le cas des aqueducs parfois appréhendés de façon erronée par al-Bakrî et son compilateur pour celui d'al-Masîla ${ }^{75}$ ou par al-Watwât lors de sa visite de Constantine ${ }^{76}$. Dans cette même ville, al-Bakrî̀77 ne reconnaît pas un aqueduc pourtant fameux, célébré par al-Idrîsî̀ ${ }^{78}$; le pèlerin al-Harawî signale quant à lui que ce pont " compte parmi les constructions merveilleuses du monde ${ }^{79}$ ", opinion reprise par le Kitâb al-Ibtisâr ${ }^{80}$. C'est ici l'aqueduc d'Hadrien, véritable merveille, au sens de gharib, "curiosité fabriquée par l'homme ", qui suscite généralement l'enthousiasme des visiteurs et compilateurs. D'une longueur de $100 \mathrm{~km}$, on sait qu'il fut restauré au XIII ${ }^{\mathrm{e}}$ siècle sous le calife hafside al-Mustansir ; on le nomma alors al-hanâya: les arches.

Outre les murailles des villes, les vestiges d'ouvrages fortifiés sont fréquemment évoqués sous les termes hisn / husûn ou qusûr ${ }^{81}$. Mûnastir possède selon al-Bakrî, un château antique en pierre et en chaux et un temple ${ }^{82}$, et Badja, un château antique constitué de grosses pierres ${ }^{83}$. Si ce type de vestiges abonde, en revanche, aucun auteur ne sait véritablement les dater ${ }^{84}$.

Par ailleurs, les lieux du sacré intriguent beaucoup le voyageur (tombes, stèles, temples, lieux de culte), et ce en raison de leur forme ou de leurs inscriptions indéchiffrables et illisibles, mais aussi parce que certains d'entre eux demeurent toujours des endroits fréquentés. Certains sont des lieux de culte préislamiques et polythéistes locaux : ainsi Maghmadâs, chez al-Bakrî, désigne à la fois un lieu et une sorte d'idole (sanam) entourée d'autres ${ }^{85}$. D'autres monuments sont cités : les maghdûs, mausolées berbères de forme circulaire à gradins et toujours en élévation ${ }^{86}$. Al-Idrîsis ${ }^{87}$ signale l'un d'entre eux sur l'iti-

El-Bekri, Description, p. 142.

Al-Watwât in E. FaGnan, Extraits, p. 50. De même, al-Watwât en visitant Constantine ne sait reconnaître un aqueduc et il dit que trois rivières coulent dans une profonde tranchée entourant la ville.

El-Bekri, Description, p. 151-152.

Idrîsî, La première géographie, p. 171.

Al-Harawî, in E. FaGnAN, Extraits inédits, p. 4.

Ibid., p. 24.

Idrîsî, La première géographie, p. 84.

El-Bekri, Description, Monastir, p. 79.

Ibid., p. 118-119, Badja ou Vacca romaine.

Voir sur les fortification du Maghreb, P. Gourdin, "Les fortifications du Maghreb d'après les sources écrites : la vision d'Ibn Khaldûn", in R. GYSELEN (éd.), Sites et monuments disparus d'après les témoignages des voyageurs, Res orientales, vol. VIII, 1996, p. 25-32.

En fait le terme sanam signifie certes idole, mais aussi piédestal ou stèle, et il s'agirait ici d'une colonne sur un socle rectangulaire de grès aux inscriptions effacées, située à une heure de distance de Zaffran (ibid., p. 21 : "Maghmadâs est une idole dressée sur le rivage de la mer et entourée de plusieurs autres idoles").

A. Laronde, L'Afrique antique, histoire et monuments, Paris, 2001, p. 60 ; cf. medracen à $100 \mathrm{~km}$ de Constantine (ibid., p. 64). En fait medracen ou madrès dérive de Maghdès, l'ancêtre mythique des Berbères (ibid., p. 65).

Idrîsî, La première géographie, p. 164. 
néraire d'Alger à Matifou, al-Bakrî̀ ${ }^{88}$ un autre à Madauros près d'Hippone. Les cimetières chrétiens ou catacombes intriguent et terrifient, ceux de Carthage étant particulièrement connus pour les restes humains qu'on y voient encore ${ }^{89}$.

Les monuments antiques dévolus aux spectacles (thêâtres, amphithéâtres, hippodromes) sont les plus significatifs dans leurs fonctions, en raison de leur structure souvent imposante et les géographes les citent volontiers sous les vocables al-thîatar: théâtre ; al-mu'alab : lieu de divertissement. Par exemple, Sûsa ou Sousse est décrite avec son théâtre, ses voûtes et ses nombreux monuments ; mais c'est le même terme qui désigne à la fois l'hippodrome (maydân) et l'amphithéâtre (mudarradj) : le lieu où l'on se divertit ${ }^{90}$ (mu'alab). Là encore, c'est Carthage qui concentre toute l'attention du voyageur puisque l'on y trouve l'essence de toute la civilisation préislamique dans le descriptif des lieux de loisirs, des équipements de voirie ${ }^{91}$ etc.

Tous les monuments ne sont pas nommés par leur fonction initiale, parfois pour des raisons d'histoire locale, parfois pour des raisons plus obscures. Ainsi le vocable « château " regroupe les vestiges majestueux les plus divers tel l'amphithéâtre de Ledjem (Thysdrus) qui n'est pas évoqué autrement que par "château de la Kahina " par al-Bakrị̂ ${ }^{92}$. De façon inverse, à Carthage, il nomme thiâtar, "théatre ", le château qui domine la mer ${ }^{93}$, alors qu'un autre monument qui serait un cirque (qûmash ou qirqush) est, lui, qualifié de qasr ${ }^{94}$, " château ", alors qu'il est visiblement doté d'arcades, de colonnes, etc. Peut-on en conclure que, dans la mentalité du musulman médiéval, tout ce qui est grand, majestueux, quand il n'est pas identifiable, est alors assimilé à un château ${ }^{95}$ ?

Parfois, des vestiges non identifiés sont présentés par l'usage qui en est fait, tout comme à Tebessa (Théveste) où les voyageurs s'abritent dans des salles voûtées en pierre de taille, possibles vestiges de thermes ou de citernes ${ }^{96}$. Concernant Carthage, al-Gharnatî présente des lieux mystérieux décorés et dotés de souterrains qui ressemblent à un cirque, un amphithéâtre ou ses dépendances ${ }^{97}$. Dans la même lignée, à Cherchell, l'Anonyme du XII ${ }^{\mathrm{e}}$ siècle présente une construction remarquable " appelée Mihrâb de Salomon qui s'élève à une grande hauteur dans les airs ${ }^{98}$ ", qui est en réalité l'arc de triomphe de Caracalla...

$88 \quad$ El-Bekri, Description, p. 107.

89 El-Bekri, Description, p. 92 et 94-95.

$90 \quad$ Ibid., p. 74-75.

91 Ibid., p. 92 et $94-95$.

92 Ibid., p. 48.

$93 \quad$ Ibid., p. 93 et 43.

$94 \quad$ Ibid., p. 94.

95 Selon Ibn Khaldûn la ville est d'abord une forteresse, signe de l'importance des fortifications dans le monde musulman : voir P. Gourdin, Les fortifications, p. 28-30.

$96 \quad$ Ibid., p. 323.

97 Kitâb al-Ibtisâr, in E. FAGnAN (éd.), p. 32.

98 Ibid., p. 40. 
Il semblerait donc que tous les monuments n'aient pas eu une signification bien explicite : le fonctionnement du cirque, l'arc de triomphe, l'usage du temple, voire de l'aqueduc, demeurent au fond un peu mystérieux et les visiteurs, faute de repères, en dehors des thermes, en réinventent l'usage selon leur imagination et leurs besoins...

\section{Les ruines, lieux de mémoire ou lieux détournés ?}

\section{L'appropriation de la ruine et son usage actif détourné : la seconde vie des ruines}

Bien des monuments continuent à vivre, soit de leur fonction première, soit d'une ré-appropriation tels les murs des villes de construction ancienne qui font toujours office de murailles mais aussi certains des ouvrages fortifiés tel, selon al-Bakrị̂9, le château de Lebda (Leptis Magna).

Les historiens de l'art et les archéologues ont tous souligné le remploi de matériaux antiques dans la construction et le décor des mosquées et des palais des dynastes musulmans (colonnes et chapiteaux en particulier). Al-Gharnatî signale ainsi que les monuments sont pillés de leur marbre embarqué par cargaison entière de par les mers ${ }^{100}$. Al-Idrîsî, en décrivant Carthage, exprime sa vive admiration pour ses bâtisseurs et il souligne le pillage permanent et universel de ses marbres, colonnes, chapiteaux ${ }^{101}$. C'est évidemment le marbre qui semble avoir la préférence des populations, mais l'usage et la destination du remploi ne sont pas spécifiés. Il semble seulement que les activités de pillage et de revente soient assez lucratives... D'autres ruines ont un usage pratique, comme un des temples de Sûsa servant de phare selon al-Bakrî ${ }^{102}$. Dans une vision ludique voire onirique, les ruines sont également perçues comme des sortes de " merveilles " ou "gharâib al-mawjûdât» (curiosités de la création humaine), que l'on vient explorer en se promenant, comme l'explique fréquemment al-Bakrî ${ }^{103}$.

\section{Le problème de la merveille, vestige imaginaire}

Les géographes, soit par leur volonté d'exhaustivité, soit par prétention encyclopédique, se distinguent toutefois des récits rapportés par la géographie des merveilles, celle d'alMas'ûdî ou d'Ibn al-Faqîh, récits que dénonce avec vigueur Ibn Khaldûn. De ce fait le vestige imaginaire, « la merveille » au sens " 'ajîb » en somme, est un fait rare. Pourtant

\footnotetext{
99 El-Bekri, Description, p. 25.

100 Abû Hamîd al-Andalûsi ('Abd al-Rahîm al-Gharnatî), in E. FAGnAn, Extraits, p. 32.

101 Idrîsî, La première géographie, p. 190.

102 Ibid., p. 78.

103 El-Bekri, Description, p. 96.
} 
ce type de curiosité est proposé par al-Bakrî, qui évoque l'existence d'un miroir magique révélant les faits tenus secrets ${ }^{104}$.

\section{3. États d'âme et restes du passé}

L'évocation des vestiges du passé est assez prolifique : les géographes musulmans, tant orientaux qu'occidentaux, prennent plaisir à décrire ce qu'ils voient lors de leurs pérégrinations dans des sites mystérieux, au milieu de monuments peu intelligibles. Ainsi, l'intérêt de ces voyageurs curieux précède-t-il de quelques siècles la passion occidentale pour les ruines, liée en grande partie à la redécouverte de l'Antiquité romaine par Lorenzo Valla ou Vasari, phénomène qui se développa et s'amplifia avec l'invention de l'archéologie scientifique et l'engouement des peintres et des hommes de lettres aux $\mathrm{XVIII}^{\mathrm{e}}$ et $\mathrm{XIX}^{\mathrm{e}}$ siècles ${ }^{105}$, et qui atteindra son paroxysme avec la fabrication de ruines artificielles ou de faux monuments antiques ${ }^{106}$.

En fait, si l'émotion suscitée par la ruine est centrale dans l'esthétisme du $\mathrm{XVIII}^{\mathrm{e}}$ siècle ${ }^{107}$, elle s'apparente à un goût du faux plutôt qu'à l'émotion née de la ruine elle-même consacrée par le mouvement romantique. Était-ce déjà le cas à l'époque médiévale ? Aimait-on les ruines, comme lieu de promenade, pour l'émotion esthétique, ou pour l'émotion éprouvée face au témoignage du passé ?

Tous les voyageurs, ou compilateurs, insistent sans restriction sur la beauté et la grandeur des ruines, la qualité et la solidité des matériaux, l'ingéniosité des bâtisseurs, l'aspect récent de certains monuments. Al-Bakrî, par exemple, souligne les artifices techniques des constructeurs et l'usage de matériaux légers comme à Sousse/Sûsa ${ }^{108}$ :

Ce vaste édifice de construction antique est posé sur des voûtes très larges et très hautes dont les cintres sont en pierres ponces, substance assez légère pour flotter sur l'eau et que l'on retire du volcan de la Sicile. Autour du Melab se trouve un grand nombre de voûtes communiquant les unes avec les autres. Dans les environs de la ville on voit des ruines d'une grandeur énorme et d'une haute antiquité. Sûsa est entièrement bâtie en pierres de taille [...]

104 Ibid., p. 74.

105 Méditation et description de Rousseau du Pont du Gard, de Gibbon et du Capitole, de Volerey et de Palmyre, puis avec le mouvement romantique au XIX ${ }^{\mathrm{e}}$ siècle, voir E. WANNING HaRries, The Unfinished Manner, Essays on the Fragment in the Later Eighteenth Century, University of Virginia, 1994.

106 Ibid., p. 62. Le cas le plus célèbre est celui du pavillon de Magdaleneneklausse construit en 1725-26 en Bavière. Voir entre autres V.-A. Deshoulières, P. VACHer (éd.), La mémoire en ruine : le modèle archéologique dans l'imaginaire moderne et contemporain, ClermontFerrand, 2000.

107 E. Wanning Harries, The Unfinished, p. 56 ; p. 62. Au XVI ${ }^{\mathrm{e}}$ siècle, c'est Vasari dans ses Vitae qui nous explique le premier qu'en peinture, une maison qui représente une ruine est une belle chose à voir.

108 El-Bekri, Description, p. 83. 
De même, solidité et grandeur caractérisent les monuments de Carthage ${ }^{109}$ :

On voit à Carthage deux châteaux nommés el-Ukhtaîn, les deux sœurs, qui sont entièrement construits en marbre et de la manière la plus solide ; ils se composent de blocs qui s'emboîtent les uns dans les autres [...].

La virtuosité des architectes du passé est célébrée par al-Bakrî qui est aussi admiratif devant la pérennité de la muraille de Qafsa ${ }^{110}$. Comme lui, les voyageurs ne sont pas indifférents à l'aspect esthétique et au talent artistique exprimés dans les œuvres figuratives si peu nombreuses, il est vrai, dans les édifices du monde musulman et tout particulièrement pour les mosaïques à thèmes animaliers ${ }^{111}$. Le plus surprenant demeure sans doute l'admiration des géographes qui n'ont pas visité les sites tel al-Idrîsî célébrant les merveilles architecturales de Carthage ${ }^{112}$, ou al-Dimashqî, plus laconique, parlant du génie de ses habitants ${ }^{113}$.

Les ruines ne sont pas seulement louées comme des lieux de flânerie, témoins de la grandeur d'un passé inconnu, mais certaines sont aussi présentées comme étant, sinon dangereuses, tout au moins malsaines. C'est ainsi que sont évoqués les endroits obscurs et terrifiants, nécropoles, citernes, où l'on peut entendre de mystérieux bruits.

Certains de ses lieux sont associés à des pratiques religieuses impies : anciennes stèles appartenant aux cultes puniques, mais surtout lieux de cultes polythéistes berbères, églises chrétiennes aux propriétés inconnues, voire lieux de cultes antiques dotés de mystérieux pouvoirs. Les ruines ou vestiges du passé inquiètent lorsqu'ils demeurent encore en activité. C'est ce qu'exprime al-Bakrî en évoquant la stèle de Guerza entre Tripoli et Oueddân ${ }^{114}$, consacrée semble-t-il à une divinité berbère ${ }^{115}$. Par ailleurs, des sacrifices furent longtemps pratiqués au sud de Tripoli, à quelques journées de marche du lieu évoqué par al-Bakrî, en l'honneur d'une divinité locale, le bélier à l'aspect solaire associé au dieu des Libyques en la personne du dieu oraculaire Ammon ${ }^{116}$. Guerza, ou

109 Ibid., p. 95.

110 Ibid., p. 100.

111 Ibid., p. 136-137 ; la même ville est dépeinte par le Kitâb al-Ibtisâr, in E. FAGNAN (éd.), p. 38.

112 Idrîsî, La première géographie, p. 188-190. " [...] Carthage est actuellement en ruines et déserte."

113 Al-Dimishqî, Manuel, p. 331.

114 El-Bekri, Description, p. 31 : «À trois journées de Qasr ibn Maymûn on rencontre une idole de pierre dressée sur une colline et appelée Guerza. Jusqu’à nos jours les tribus berbères lui offrent des sacrifices ; elles lui adressent des prières pour obtenir la guérison de leurs maladies et lui attribuent le pouvoir de faire accroître leurs richesses. "

115 A. LaRonde, L'Afrique, p. 60. L'existence de stèles votives dédiées à Baal Ammon, furent nombreuses à l'époque romaine comme l'évoque Corippus au vi ${ }^{\mathrm{e}}$ siècle, dans ses vers, en décrivant une idole de Guirza, qui serait en fait le dieu Ammon Corniger.

116 J.-J. CALlot, Recherches sur les cultes en Cyrénä̈que durant le Haut Empire romain, Paris, 1999 , p. 72. 
Gurzil, était dans l'antiquité le protecteur des Libyques, identifié à Hélios, à Zeus Ammon ou à Apollon, et représenté comme un taureau. Cette stèle attesterait donc la survivance d'un culte syncrétique ancien signalé par saint Athanase (III $-\mathrm{IV}^{\mathrm{e}}$ siècles) ${ }^{117}$ en l'honneur de Guerza ${ }^{118}$, une divinité toujours adorée sous forme de bétyle ${ }^{119}$.

D’autres lieux de cultes se voient investis de propriétés magiques ou encore sont soupçonnés de receler des trésors (thème habituel de l'imaginaire des peuples sur les ruines), et d'être hantés par des esprits ${ }^{120}$. Ainsi Tebessa, la ville antique, serait dotée de temples mystérieux, l'un, à l'atmosphère étrange, marqué par les rites magiques qui y étaient pratiqués (fumigations ou sacrifices ?) et qui semblent avoir souillé les lieux, l'autre, par la présence d'étranges figures présentées comme des talismans ${ }^{121}$. Les objets décrits sont soit des figures inintelligibles pour le voyageur qui les assimile à des objets magiques, soit des figures en effet réputées comme telles. C'est le cas des scorpions dont l'effigie est utilisée comme apotropaion depuis la période hellénistique selon les principes enseignés par le magicien Apollonios de Tyane. Al-Bakrî évoque aussi la nécropole de Carthage et l'étrange phénomène acoustique émanant des citernes qui remplissaient les visiteurs de crainte mais qui servait également à éprouver la vaillance des hommes ${ }^{122}$.

Un ensemble de caractéristiques relatives à la ruine se dégage de ces récits qui reposent pour l'essentiel sur al-Warrâq via al-Bakrî, sur l'anonyme du XII siècle, ou sur Jean Léon l'Africain. La ruine est un lieu ancien, difficile à dater et à l'abandon ; elle sert de carrière, de lieu de promenade et de distraction, mais elle peut éventuellement resservir comme château, réservoir, aqueduc ou lieu de pratiques religieuses illicites... Elle suscite souvent un sentiment mêlé d'admiration pour les prouesses et la solidité de sa construction et de ses décors, mais aussi de crainte pour les pouvoirs qu'on lui prête, car elle émane d'un passé méconnu et d'une culture étrangère à l'islam.

Les témoignages des géographes ont cependant leurs limites car peu d'entre eux, au demeurant, peuvent être retenus ou confrontés. Certains ne s'intéressent aucunement au passé et encore moins à l'évocation des origines, de l'histoire ou des ruines. Tous n'ont pas visité la région, certains se recopient : l'anonyme du XII sur al-Bakrî ; al-'Umarî sur al-Idrîsî lequel n'a pas beaucoup voyagé mais s'est documenté. La plupart

117 Ibid., p. 74 ; Corripus, Johannis, I, 109-111 et 405 parle de Gurzil.

118 F. Decret, M. FAnTAR, L'Afrique du Nord dans l'Antiquité : histoire et civilisation des origines au ve siècle, Paris, 1998, p. 256.

119 Sanam: pierre sculptée en forme d'homme ou d'animal.

120 El-Bekri, Description, p. 120, p. 155.

121 Kitâb al-Ibtisâr, in E. FAGnAN (éd.), p. 91 : " On trouve encore d'autres talismans dans les ruines, où j'ai pénétré et où j'ai reçu d'un habitant l'une de ces figures symboliques, consistant en deux lions de cuivre rouge adossés par la partie postérieure du corps et sculptés de la plus merveilleuse façon."

Ibid., p. 23. 
des grands voyageurs sont muets sur l'existence de vestiges : Ibn Khurradâdhbih ; al-Yaqûbî ; Ibn Hawqal ; al-Muqaddasî ; Ibn Djubayr ; Ibn Battûta. Pourquoi ce silence ? Les raisons semblent multiples : Ibn Hawqal ou al-Muqaddasî écrivent une géographie humaine qui se préoccupe de l'activité, des hommes, de l'économie et du commerce, et ils dressent un tableau positif de l'empire. Ibn Djubayr et Ibn Battûta ont des préoccupations un peu semblables : observer les activités et les hommes, dans un but commercial et politique pour l'un, plus géographique pour l'autre. Par ailleurs, bien des vestiges ou des monuments notoires du passé préislamique ne sont pas systématiquement évoqués. Par exemple, l'arc de Caracalla, la forteresse byzantine, la basilique sainte Crispine et bien d'autres lieux célèbres de Tébessa (Théveste) ; de même à la citadelle byzantine, le mausolée berbère d'Hammaedara-Haïdra, etc. : tous sont visiblement oubliés dans ces descriptions.

En revanche on peut noter que ce sont les géographes d'origine occidentale (andalous et maghrébins) qui évoquent le plus fréquemment les ruines : al-Bakrî, al-Idrîsî, l'anonyme du XII ${ }^{\mathrm{e}}$ siècle, et Jean Léon l'Africain. Tous pourtant ne sont pas des voyageurs, certains observent, d'autres utilisent des compilations, d'autres font de l'encyclopédisme, mais tous ont en commun, semble-t-il, la conscience d'appartenir à cette aire culturelle que forme le Maghreb (au sens large), caractéristique pour son peuplement, ses langues, et aussi son histoire. On peut ainsi comprendre qu'al-Yaqûbî ou d'autres décrivent en quantité des merveilles et des vestiges orientaux mais pas occidentaux, car eux n'appartiennent pas à cette aire culturelle.

Par ailleurs, entre le $\mathrm{XI}^{\mathrm{e}}$ et le $\mathrm{XV}^{\mathrm{e}}$ siècle, l'intérêt pour la ruine semble diminuer ${ }^{123}$. Si l'intérêt pour le passé et ses restes est perceptible aux XI ${ }^{\mathrm{e}}$-XII ${ }^{\mathrm{e}}$ siècles, Jean Léon l'Africain évoque, lui, peu de sites antiques, non tant parce qu'ils ont disparu, mais parce que visiblement le regard sur le passé a changé. L'évocation de la ruine conforte la conclusion faite par Ahmed Siraj au terme de son étude ${ }^{124}$ :

Nous sommes donc loin d'écrire une histoire ancienne à partir des sources arabes, ce ne sont que des débris qui reflètent en fait une conception ou une optique : celle qui est élaborée par l'historiographie arabe.

L'ignorance partielle des géographes vis-à-vis de l'histoire locale ne gomme cependant pas leur conscience d'être les successeurs d'une histoire riche et glorieuse dans une région désormais musulmane depuis quelques siècles, signe de l'indéniable prééminence de l'islam. Si la ruine alimente cette conscience, elle permet également de rattacher l'Orient, d'où sont issus les conquérants arabes, à cet Occident lointain par le 
biais d'éléments issus de l'imaginaire collectif, prophètes tels Salomon ou al-Khidr ${ }^{125}$, ou héros de légendes à l'image d'Alexandre le Grand dont les peuples musulmans dans leur globalité de l'Atlantique à l'Asie centrale ${ }^{126}$ revendiquent la geste, dans sa dimension épique et eschatologique.

On peut observer qu'il n'existe pas aux époques qui nous occupent d'herméneutique de la ruine, encore moins un parcours artistique ou sentimental lié à la redécouverte d'un passé réel ou imaginaire. La ruine n'est que l'un des éléments du paysage de la région visitée, au même titre que les paysages cultivés ou les populations y vivant, et si elle retient l'intérêt du voyageur c'est aussi par les usages détournés qui en sont faits, signalant de façon explicite que l'islam a triomphé d'autres peuples, eux-mêmes dignes d'admiration. Ainsi les vestiges du passé connaissent-ils ainsi une seconde vie, réappropriés et associés à la destinée des peuples musulmans, signes matériels encore visibles, témoignages certes fragiles et dégradés mais cependant si précieux pour la construction d'une mémoire collective ${ }^{127}$.

\begin{tabular}{l} 
Anna CAIOZZO \\
\hline Université Paris Diderot \\
EA 337 Identités-Cultures-Territoires (ICT) \\
UMR 8167 islam médiéval \\
anna.caiozzo@univ-paris-diderot.fr
\end{tabular}

125 F. Aubaile-Sallenave, "Al-Khidr, l'homme au manteau vert en pays musulman et ses fonctions, ses caractères, sa diffusion ", R. GYSELEN (éd.), Chaînes et sortilèges, magie et magiciens, Res Orientales 14 (2002), p. 11-31.

126 C. Picard, Récits, p. 80 et A. Caiozzo, "L'image de l'Europe et des Européens dans les représentations de l'Orient médiéval ", Actes du colloque de Cluj-Napoca : L'imaginaire des Européens, 2005, Echinox 10 (2006), p. 84-120 et S.N. ABAŠIN, «Le culte d'Iskandar Zu-1Qarnayn chez les montagnards d'Asie centrale ", Cahiers d'Asie centrale 11-12 (2003), p. 61-86.

127 A. Beschaouch, La légende de Carthage, Paris, 1993, p. 41 : «El Bekri et Idrisi seront avant Ibn Khaldun les derniers grands témoins dans le monde arabo-musulman du prestige de la Carthage antique qu'ils font figurer dans leurs manuscrits et leurs cartes. » 